\title{
Significance of Pre-treatment Interferon-gamma Release in Patients With Non-small-cell Lung Cancer Receiving Immune Checkpoint Inhibitors
}

\author{
TOMONORI HIRASHIMA ${ }^{1}$, TOMOHIRO KANAI ${ }^{1,2}$, HIDEKAZU SUZUKI $^{1}$, HIROKO YOSHIDA $^{3}$, \\ AKANE MATSUSITA $^{3}$, HIROMI KAWASUMI ${ }^{3}$, SHINGO NASU $^{1}$, AYAKO TANAKA ${ }^{1}$, \\ NAOKO MORISHITA $^{1}$, KUNIMITSU KAWAHARA ${ }^{4}$, YOSHITAKA TAMURA ${ }^{3}$ and NORIO OKAMOTO ${ }^{1}$ \\ ${ }^{I}$ Department of Thoracic Oncology, Osaka Habikino Medical Center, Osaka, Japan; \\ ${ }^{2}$ Department of Respiratory Medicine. Osaka General Medical Center, Osaka, Japan; \\ ${ }^{3}$ Department of Clinical Laboratory, Osaka Habikino Medical Center, Osaka, Japan; \\ ${ }^{4}$ Department of Clinical Pathology, Osaka Habikino Medical Center, Osaka, Japan
}

\begin{abstract}
Background/Aim: We retrospectively investigated the significance of pre-treatment interferon-gamma release (IGR) as a biomarker for predicting the efficacy of immune checkpoint inhibitor treatment (ICI-tx). Patients and Methods: This study included non-small-cell lung cancer patients who received ICI-tx between January 1, 2016 and April 30, 2019. IGR was measured using the positive control of an enzyme-linked immunosorbent assay. We defined the pre-treatment cut-off level of IGR as $10 \mathrm{IU} / \mathrm{ml}$. Results: Fiftyfour patients were divided into two groups; those with an IGR $\leq 10 \mathrm{IU} / \mathrm{ml}$ (lower group: $L G)(n=15)$ and those with $>10 \mathrm{IU} / \mathrm{ml}$ (higher group: $H G)(n=39)$. The time to treatment failure (TTF) in the $H G$ was significantly longer than that in the LG. In multivariate analyses, $C$-reactive protein and IGR levels were significant risk factors for TTF. Conclusion: Pretreatment IGR level of $>10 \mathrm{IU} / \mathrm{ml}$ is recommended to identify those patients who will respond favourably to ICI-tx.
\end{abstract}

Several studies (1-3) have indicated that the programmed cell death 1 (PD-1)/PD-1 ligand 1 (PD-L1) axis and interferongamma $(\mathrm{IFN}-\gamma)$ are important for acquiring cellular immunity to Mycobacterium Tuberculosis (MTB). In a previous study (4), we measured the IFN $-\gamma$ release (IGR) levels in the phytohemagglutinin (PHA)-containing positive

This article is freely accessible online.

Correspondence to: Tomonori Hirashima, MD, Department of Thoracic Oncology, Osaka Habikino Medical Center, 3-7-1, Habikino, Habikino city, Osaka, 583-8588, Japan. Tel: +81 729572121, Fax: +81 729578002, e-mail: hirashimat@ra.opho.jp

Key Words: Interferon-gamma release, immune checkpoint inhibitor, non-small-cell lung cancer, biomarker, time to treatment failure. control (PC) of the QuantiFERON ${ }^{\circledR}$-TB Gold Plus (QFTTBGP) enzyme-linked immunosorbent assay. We showed changes in IGR in the PC after immune checkpoint inhibitor treatment (ICI-tx), and demonstrated the potential of IGR as a biomarker. Furthermore, our subsequent study (5) demonstrated that patients with a PC IGR level $>7.06 \mathrm{IU} / \mathrm{ml}$ prior to ICI-tx had significantly longer progression-free survival than those with a PC IGR level $7.06 \mathrm{IU} / \mathrm{ml}$. Huang et al (6). similarly reported that among non-small cell lung cancer (NSCLC) patients treated with chemotherapy, those with an IGR level $>7.06 \mathrm{IU} / \mathrm{ml}$ in the PC had significantly better survival than those with an IGR level $7.06 \mathrm{IU} / \mathrm{ml}$. Further, Langan et al. (7) performed MTB screening in 70 patients who underwent immune checkpoint inhibitor therapy for metastatic skin cancer, and subsequently recommended $M T B$ screening before ICI-tx.

In this study, we defined the IGR cut-off level in the PC prior to ICI-tx as $10 \mathrm{IU} / \mathrm{ml}$. We enrolled patients with NSCLC who received ICI-tx alone, and retrospectively examined the difference in treatment efficacy between patients whose IGR levels were $>10 \mathrm{IU} / \mathrm{ml}$ and those with IGR levels $<10 \mathrm{IU} / \mathrm{ml}$. Furthermore, we assessed patients with positive QFT-TBG or QFT-TBGP tests to determine whether they developed $M T B$.

\section{Patients and Methods}

Ethics. The study protocol was approved by the institutional review board of the Osaka Habikino Medical Center (formerly the Osaka Prefectural Medical Center for Respiratory and Allergic Diseases, Osaka, Japan) on May 5, 2020 (approval number: 1020). The requirement for informed consent was waived due to the retrospective study design and the anonymization of the data. All research was conducted in accordance with the 1964 Declaration of Helsinki and its later amendments. The details regarding our institution's opt-out policy are available at homepage of this institution (8). 
Table I. Patient demographics.

\begin{tabular}{|c|c|c|c|c|}
\hline \multirow[t]{2}{*}{ Variables } & \multirow[t]{2}{*}{ Overall } & \multicolumn{2}{|c|}{ IGR (IU/ml) level } & \multirow[t]{2}{*}{$p$-Value } \\
\hline & & $\leq 10(\mathrm{n}=15)$ & $>10(n=39)$ & \\
\hline \multicolumn{5}{|l|}{ Gender } \\
\hline Male & 46 & 15 & 31 & \multirow[t]{2}{*}{0.089} \\
\hline Female & 8 & 0 & 8 & \\
\hline \multicolumn{5}{|l|}{ Age } \\
\hline Mean (range) & $69.0(42-84)$ & $68.8(42-83)$ & $69.0(44-84)$ & 0.923 \\
\hline \multicolumn{5}{|l|}{ Smoking status } \\
\hline Ever & 47 & 15 & 32 & \multirow[t]{2}{*}{0.171} \\
\hline Never & 7 & 0 & 7 & \\
\hline \multicolumn{5}{|l|}{ Performance status } \\
\hline $0-1(0 / 1)$ & $37(4 / 33)$ & $7(0 / 7)$ & $30(4 / 26)$ & \multirow[t]{2}{*}{0.069} \\
\hline $2-3(2 / 3)$ & $17(15 / 2)$ & $8(6 / 2)$ & $9(9 / 0)$ & \\
\hline \multicolumn{5}{|l|}{ Histology } \\
\hline Adenocarcinoma & 39 & 10 & 29 & \multirow[t]{3}{*}{0.821} \\
\hline Squamous cell carcinoma & 12 & 3 & 9 & \\
\hline Others & 3 & 2 & 1 & \\
\hline \multicolumn{5}{|l|}{ Tuberculosis infection } \\
\hline Latent or past & 7 & 2 & 5 & \multirow[t]{2}{*}{1.000} \\
\hline No & 47 & 13 & 34 & \\
\hline \multicolumn{5}{|l|}{ Stage } \\
\hline IIIB-C & 8 & 2 & 6 & \multirow[t]{3}{*}{0.747} \\
\hline IV & 28 & 7 & 21 & \\
\hline Recurrence & 18 & 6 & 12 & \\
\hline \multicolumn{5}{|l|}{ PD-L1 staining } \\
\hline$<1 \%$ & 10 & 3 & 7 & \multirow[t]{4}{*}{1.000} \\
\hline$\geq 1 \%,<50 \%$ & 14 & 4 & 10 & \\
\hline$\geq 50 \%$ & 23 & 7 & 16 & \\
\hline Unknown & 7 & 1 & 6 & \\
\hline \multicolumn{5}{|l|}{ Driver mutation } \\
\hline Yes & 5 & 2 & 3 & \multirow[t]{3}{*}{0.610} \\
\hline No & 41 & 11 & 30 & \\
\hline Unknown & 8 & 2 & 6 & \\
\hline \multicolumn{5}{|l|}{ Treatment Line } \\
\hline First & 22 & 8 & 14 & 0.390 \\
\hline Second & 20 & 1 & 19 & \\
\hline Third or more & 12 & 6 & 6 & \\
\hline ICI & & & & \\
\hline Pembrolizumab & 23 & 7 & 16 & 0.946 \\
\hline Atezolizumab & 8 & 2 & 6 & \\
\hline Nivolumab & 23 & 6 & 17 & \\
\hline BMI $\left(\mathrm{kg} / \mathrm{m}^{2}\right)$ & & & & \\
\hline Mean (range) & $22.7(16.0-32.8)$ & $20.6(17.6-24.6)$ & $23.5(16.0-32.8)$ & 0.009 \\
\hline Under weight $(<18.5)$ & 3 & 1 & 2 & \\
\hline Normal weight $(\geq 18.5,<25.0)$ & 38 & 14 & 24 & \\
\hline Pre-obesity or Obesity $(\geq 25.0)$ & 13 & 0 & 13 & 0.005 \\
\hline Mean Laboratory data (range) & & & & \\
\hline Neutrophil-lymphocyte ratio & $4.43(1.05-19.21)$ & $7.05(2.00-19.21)$ & $3.42(1.05-8.28)$ & 0.008 \\
\hline Serum albumin $(\mathrm{g} / \mathrm{dl})^{*}$ & $3.76(2.5-4.8)$ & $3.41(2.5-4.3)$ & $3.89(2.6-4.8)$ & 0.012 \\
\hline C-reactive protein $(\mathrm{mg} / \mathrm{dl})$ & $2.06(0.03-14.79)$ & $4.13(0.07-14.79)$ & $1.27(0.03-6.22)$ & 0.012 \\
\hline
\end{tabular}

ICI: Immune checkpoint inhibitor; BMI: body mass index; IGR: Interferon-gamma release; PD-L1: programmed cell death ligand-1. *Serum albumin levels were not examined in 2 patients with interferon-gamma levels $>10 \mathrm{IU} / \mathrm{ml}$.

Patient selection. One hundred and thirty-eight patients with NSCLC were treated with either nivolumab $(\mathrm{N}=102)$ or pembrolizumab $(\mathrm{N}=36)$ at our institution between January 1, 2016 and June 30, 2018. Of these, we selected 25 patients on whom QFT-
TBG or QFT-TBGP was performed for diagnosis of latent MTB within 14 days of ICI treatment. We also included 29 patients who were included in a previous study $(4,5)$ between July 17, 2018 and February 25, 2019. The total number of patients studied was 54 . 
Baseline patient demographics. The baseline patient demographics that we assessed before ICI treatment were sex, age, smoking status, Eastern Cooperative Oncology Group performance status (PS), body weight, height, body mass index (BMI), medications, disease complications, past illness and history of cancer treatment. BMI $\left(\mathrm{kg} / \mathrm{m}^{2}\right)$ was defined as the patient's weight in kilograms divided by the square of the patient's height in metres. Patients were categorized into the following three groups based on their BMI [according to established WHO categories (9)]: underweight $(<18.5)$; normal weight $(18.5-24.9)$; and pre-obesity or obesity $(\geq 25.0)$. Blood and biochemical tests, performed within 14 days prior to ICI-tx, included: cell counts (white blood cells, lymphocytes, and neutrophils), serum albumin (s-Alb, g/dl), and C-reactive protein (CRP, mg/dl). The neutrophil-to-lymphocyte ratio (NLR) was calculated by dividing the neutrophil count by the lymphocyte count.

Interferon-gamma release assay. The IFN- $\gamma$ release assay (IGRA) was performed in-house with QuantiFERON ${ }^{\circledR}$-TB Gold (QFT-TBG) (10) between 2016 and 2018 or with QFT-TBGP (11) between 2018 and 2019. The cut-off level of IGR in the PC was defined as 10 $\mathrm{IU} / \mathrm{ml}$, as described in the package inserts (12). Furthermore, the utility of the cut-off level of $7.06 \mathrm{IU} / \mathrm{ml}$ in the PC was reconfirmed, as established in our previous study (5). Latent tuberculosis or a past history of tuberculosis infection was determined based on the guidelines in the package inserts (12).

Time to treatment failure and overall survival. Time to treatment failure (TTF) was defined as the time between the administration of ICIs to their discontinuation for any reason, including progressive disease, treatment toxicity and death. Disease progression was determined by diagnostic imaging including computed tomography (CT), magnetic resonance imaging, bone scintigraphy and positron emission tomography, according to the Response Evaluation Criteria in Solid Tumors (RECIST) guidelines version 1.1. The time of disease progression was considered as the day on which the CT was conducted. Overall survival (OS) was defined from the time of administration of ICIs to the date of mortality or last follow-up. TTF and OS data were last updated on March 31, 2020.

Statistical analysis. All analyses were conducted using the statistical software package R. The differences in variables between two groups were evaluated using the chi-square or Mann-Whitney $U$ test for categorical variables. TTF and OS were compared using the Kaplan-Meier method and log-rank test. Differences were considered statistically significant at $p$-values $<0.05$.

\section{Results}

Baseline patient demographics. Fifty-four patients $(n=54)$ were included in this study, including those with IGR $\leq 10$ IU/ml (lower group: LG) $(\mathrm{n}=15)$, and those with IGR $>10$ $\mathrm{IU} / \mathrm{ml}$ (higher group: HG) $(\mathrm{n}=39)$ in the PC of the QFT or QFT-plus assay before ICI-tx (Table I). There were no significant differences in clinical parameters between the groups. Table I shows that mean BMI and frequency of preobesity or obesity in the HG were significantly higher than those in LG ( $p=0.009$ and $p=0.005$, respectively). Contrastingly, NLR and CRP were significantly lower in the HG than in the LG ( $p=0.008$ and $p=0.012$, respectively). In
Table II. Analysis of overall response rate and disease control rate according to variables.

\begin{tabular}{|c|c|c|c|c|c|}
\hline Variables & $\begin{array}{c}\text { Number } \\
\text { of } \\
\text { patients }\end{array}$ & $\begin{array}{c}\text { Response } \\
\text { rate } \\
(\%)\end{array}$ & $p$-Value & $\begin{array}{c}\text { Disease } \\
\text { control } \\
\text { rate }(\%)\end{array}$ & $p$-Value \\
\hline Total & 54 & $11(20.4)$ & & $20(37.0)$ & \\
\hline \multicolumn{6}{|c|}{ IGR (IU/ml) level } \\
\hline$\leq 10 \mathrm{IU} / \mathrm{ml}$ & 15 & $1(6.7)$ & \multirow[t]{2}{*}{0.153} & $3(20.0)$ & \multirow[t]{2}{*}{0.129} \\
\hline$>10 \mathrm{IU} / \mathrm{ml}$ & 39 & $10(25.6)$ & & $17(43.6)$ & \\
\hline \multicolumn{6}{|l|}{ Gender } \\
\hline Male & 46 & $11(23.9)$ & \multirow[t]{2}{*}{$<0.001$} & $17(37.0)$ & \multirow[t]{2}{*}{1.000} \\
\hline Female & 8 & $0(0)$ & & $3(37.5)$ & \\
\hline \multicolumn{6}{|l|}{ Age } \\
\hline$\leq 70$ & 26 & $7(26.9)$ & \multirow[t]{2}{*}{0.416} & $10(38.5)$ & \multirow[t]{2}{*}{0.835} \\
\hline$\geq 71$ & 28 & $4(14.3)$ & & $10(35.7)$ & \\
\hline \multicolumn{6}{|c|}{ Performance status } \\
\hline $0-1$ & 37 & $9(24.3)$ & \multirow[t]{2}{*}{0.293} & 18 (48.6) & \multirow[t]{2}{*}{0.014} \\
\hline $2-3$ & 17 & $2(11.8)$ & & $2(11.8)$ & \\
\hline \multicolumn{6}{|l|}{ Histology } \\
\hline Ad & 39 & $7(17.9)$ & \multirow[t]{2}{*}{0.737} & $14(35.9)$ & \multirow[t]{2}{*}{0.972} \\
\hline non-Ad & 15 & $4(26.7)$ & & $6(40.0)$ & \\
\hline \multicolumn{6}{|c|}{ PD-L1 staining } \\
\hline$<50 \%$ & 25 & $4(16.0)$ & \multirow[t]{2}{*}{0.849} & $10(40.0)$ & \multirow[t]{2}{*}{0.542} \\
\hline$\geq 50 \%$ & 22 & $4(18.2)$ & & $6(27.3)$ & \\
\hline \multicolumn{6}{|l|}{ Stage } \\
\hline IV & 28 & 14.3 & \multirow[t]{2}{*}{0.416} & 28.6 & \multirow[t]{2}{*}{0.291} \\
\hline non-IV & 26 & 26.9 & & 46.2 & \\
\hline \multicolumn{6}{|l|}{ Treatment line } \\
\hline 1 & 22 & 22.7 & \multirow[t]{2}{*}{0.989} & 31.8 & \multirow[t]{2}{*}{0.710} \\
\hline$\geq 2$ & 32 & 21.9 & & 40.6 & \\
\hline \multicolumn{6}{|c|}{ Body mass index } \\
\hline$<22 \mathrm{~kg} / \mathrm{m}^{2}$ & 27 & $5(18.5)$ & \multirow[t]{2}{*}{1.000} & $9(33.3)$ & \multirow[t]{2}{*}{1.000} \\
\hline$\geq 22 \mathrm{~kg} / \mathrm{m}^{2}$ & 27 & $6(22.2)$ & & $10(40.7)$ & \\
\hline $\begin{array}{l}\text { Neutrophil-to } \\
\text { lymphocyte }\end{array}$ & & & & & \\
\hline$<3.6$ & 27 & $8(29.6)$ & 0.175 & $10(37.0)$ & 1.000 \\
\hline$\geq 3.6$ & 27 & $3(11.1)$ & & $10(37.0)$ & \\
\hline Serum album & & & & & \\
\hline$<4.0 \mathrm{~g} / \mathrm{dl}$ & 27 & $5(18.5)$ & 0.886 & $7(25.9)$ & 0.173 \\
\hline$\geq 4.0 \mathrm{~g} / \mathrm{dl}$ & 25 & $6(24.0)$ & & $12(48.0)$ & \\
\hline C-reactive pr & & & & & \\
\hline$<0.6 \mathrm{mg} / \mathrm{dl}$ & 27 & $8(29.6)$ & 0.175 & $15(55.6)$ & 0.009 \\
\hline$\geq 0.6 \mathrm{mg} / \mathrm{dl}$ & 27 & $3(11.1)$ & & $5(18.5)$ & \\
\hline
\end{tabular}

IGR: Interferon gamma release; PD-L1: programmed cell death ligand1; Ad: adenocarcinoma.

contrast, s-Alb was significantly higher in the HG than in the LG $(p=0.012)$. s-Alb was not examined in two patients.

Response to immune checkpoint inhibitor treatment. The analysis of the response rate (RR) and disease control rate (DCR) by each variable (Table II) showed that RR in all patients was $20.4 \%$ and DCR in all patients was $37.0 \%$. Males had significantly higher RR $(23.9 \%)$ than females $(0 \%)$ $(p<0.001)$. The DCR $(48.6 \%)$ in patients with PS between $0-$ 1 was significantly higher than that $(11.8 \%)$ in those with a 
Table III. Immune-related adverse events.

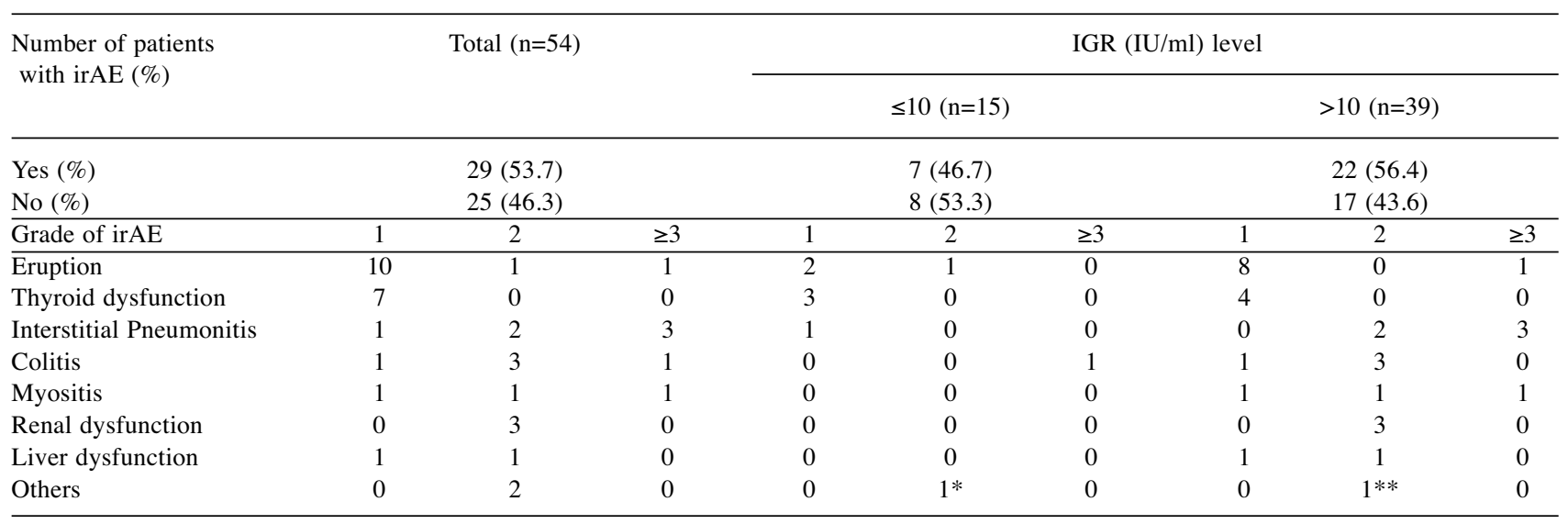

irAE: Immune-related adverse events; IGR: interferon-gamma release. *Grade 2 diabetes mellitus; ${ }^{*}$ Grade 2 adrenal dysfunction. No patient died of immune related adverse events.

PS between 2-3 ( $p=0.014)$. The DCR $(55.6 \%)$ in patients with CRP $<0.6 \mathrm{mg} / \mathrm{dl}$ was significantly higher than that in patients with CRP $\geq 0.6 \mathrm{mg} / \mathrm{dl}(18.5 \%)(p=0.009)$.

Immune-related adverse events. As shown in Table III, some degree of immune-related adverse events (irAEs) was observed in $29(53.7 \%)$ of 54 patients. The most frequent irAE was eruption, observed in 12 patients (LG/HG: 3/9), thyroid dysfunction [7 patients (LG/HG: 3/4)], ICI-induced interstitial pneumonitis (ICI-IP) [6 patients (LG/HG: 1/5)], colitis [5 patients (LG/HG: 1/5)], myositis [3 patients (LG/HG: 0/3)], renal dysfunction [3 patients (LG/HG: 0/3)], and liver dysfunction [2 patients (LG/HG: 0/2)]. One patient experienced diabetes mellitus and one experienced adrenal dysfunction. No patients died of irAEs.

Kaplan-Meier curves for time to treatment failure and overall survival. HG patients had a significantly longer OS (483 days) as compared to LG patients (304 days; Figure 1A) $(p=0.008)$. Similarly, the median TTF in the HG ( 84 days) was significantly longer than that in LG (21 days; Figure 1B) $(p=0.023)$.

When an IGR cut-off level of $7.06 \mathrm{IU} / \mathrm{ml}$ was used (Figure 1C), the median OS in the HG (415 days) tended to be longer than that in the LG (291 days) $(p=0.070)$. Similarly, the median TTF was significantly longer in the HG (78 days) than in the LG (21 days; Figure 1D) $(p=0.041)$.

Univariate analyses and multivariate analyses for time to treatment failure. Of the 54 patients enrolled in this study, 40 patients discontinued ICI-tx due to disease progression, 9 due to irAEs; 1 refused ICI-tx, and 4 continued it. Amongst the 9 patients who discontinued ICI-tx due to irAEs, 5 experienced interstitial pneumonitis (G1/2/3: 1/1/3), 2 experienced G2 renal dysfunction, and 1 each experienced G3 colitis and G3 eruption, respectively. As shown in Table IV, in univariate analyses for TTF, PS $(p=0.001)$, stage $(p=0.017), \mathrm{NLR}(p=0.025), \mathrm{s}-\mathrm{Alb}(p=0.003), \mathrm{CRP}(p<0.001)$, and IGR $(p=0.023)$ levels were all significant risk factors for ICI-tx failure. s-Alb was excluded from multivariate analysis because of missing data for 2 patients. In multivariate analyses, CRP and IGR levels were significant risk factors for TTF ( $p=0.008$ and $p=0.041$, respectively).

Patients with a positive interferon-gamma release assay (IGRA). In this study, 7 of 54 patients had a positive IGRA test. Amongst these patients, 6 were diagnosed with latent $M T B$, whereas 1 patient received anti-MTB treatment while receiving ICI-tx. None of these patients developed active $M T B$ infection or recurrence of $M T B$ infection.

\section{Discussion}

In this retrospective study, we demonstrated that TTF and OS in the HG were significantly longer than those in the LG when the pre-ICI-tx IGR cut-off level of the positive control was set at $10 \mathrm{IU} / \mathrm{ml}$. In multivariate analysis, CRP and IGR levels were identified as significant risk factors for TTF. The difference in TTF at an IGR cut-off of $10 \mathrm{IU} / \mathrm{ml}$ was clearer than that with a cut-off of $7.06 \mathrm{IU} / \mathrm{ml}$. Therefore, based on our findings we recommend that $10 \mathrm{IU} / \mathrm{ml}$ should be used as the cut-off value to identify patients that will have a favourable response to ICI-tx.

Huang et al. (6) has previously reported that a higher pretreatment PHA-stimulated IFN- $\gamma$ response (high-PHA) was associated with better survival among advanced NSCLC patients treated with chemotherapy. These findings are similar to those of our previous study (5), in which we suggested that 
A
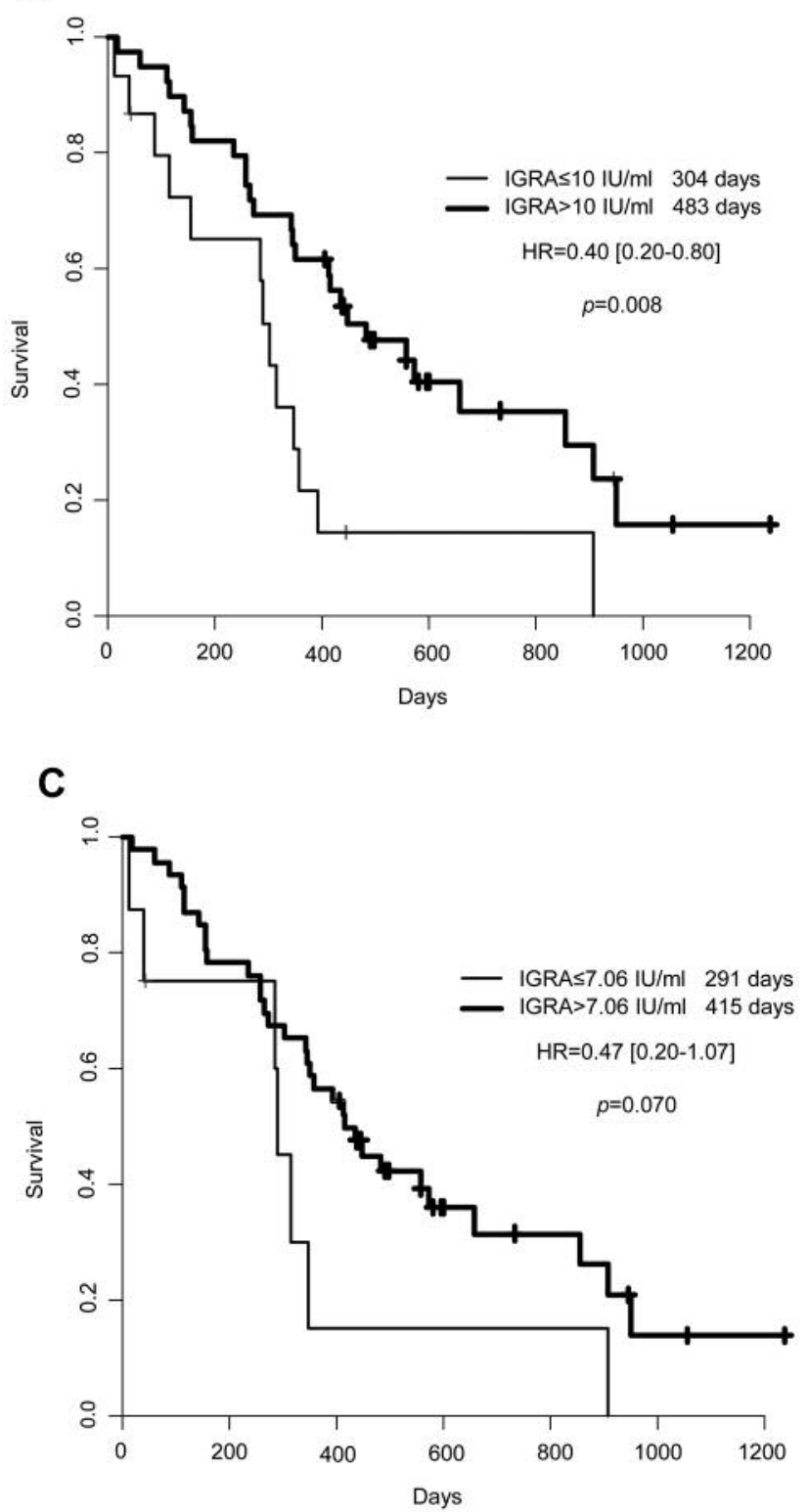

B

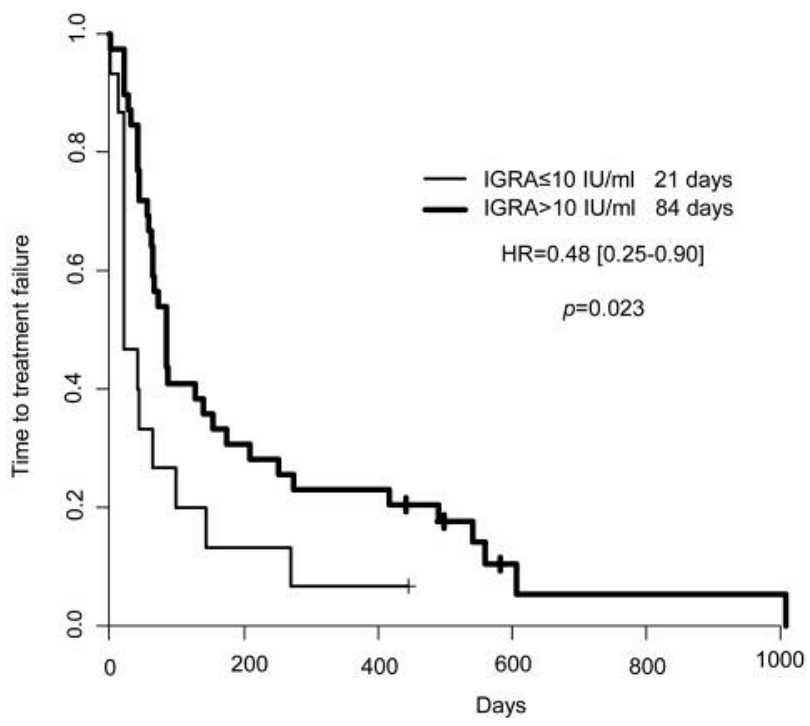

D

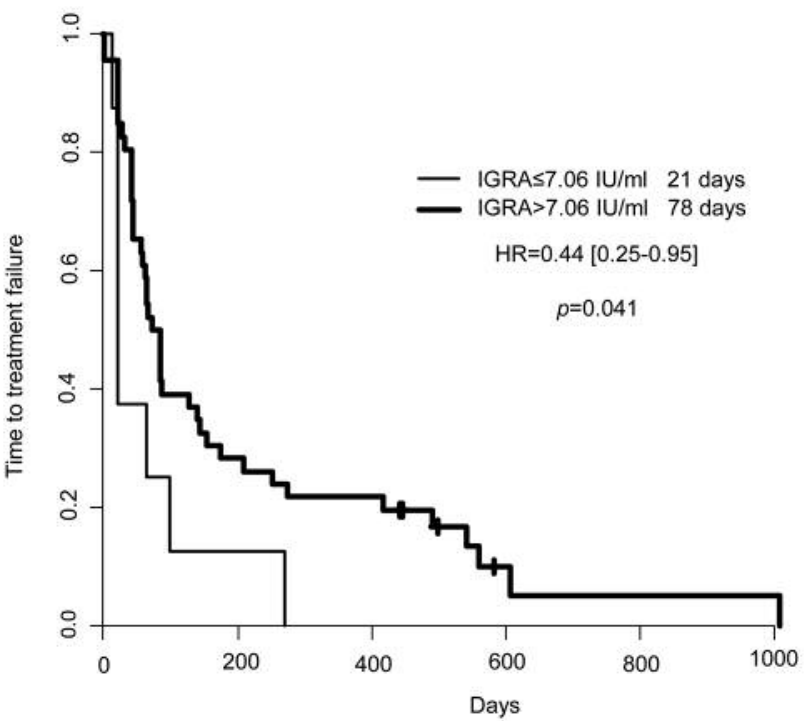

Figure 1. Time to treatment failure (TTF) and overall survival (OS) in patients with non-small-cell lung cancer using an interferon-gamma release (IGR) level cut-off of $10 \mathrm{IU} / \mathrm{ml}$ or $7.06 \mathrm{IU} / \mathrm{ml}$ prior to treatment with immune checkpoint inhibitors. Kaplan-Meier curves for TTF and OS indicate patients above the IGR cut-off level (in thick line) and those at or below the IGR cut-off level (thin line). A) The median OS in patients with IGR level $>10 \mathrm{IU} / \mathrm{ml}$ (483 days) was significantly longer than that with IGR $\leq 10 \mathrm{IU} / \mathrm{ml}$ (304 days) [ $p=0.008$, HR=0.40 (0.20-0.80)]. B) The median TTF (84 days) in patients with IGR level $>10 \mathrm{IU} / \mathrm{ml}$ was significantly longer than that with IGR level $\leq 10 \mathrm{IU} / \mathrm{ml}(21$ days) [p=0.023, Hazard ratio $(H R)=0.48(0.25-0.90)]$. C) When using an IGR cut-off level of $7.06 \mathrm{IU} / \mathrm{ml}$, the median OS of patients with IGR level $>7.06$ IU/ml (415 days) tended to be longer than that of patients with IGR level $\leq 7.06 \mathrm{IU} / \mathrm{ml}$ (291 days) [p=0.070, HR=0.47 (0.20-1.07)]. D) The median TTF in patients with IGR level $>7.06 \mathrm{IU} / \mathrm{ml}$ (78 days) was significantly longer than that with IGR level $\leq 7.06 \mathrm{IU} / \mathrm{ml}$ (21 days) [p=0.041, HR=0.44 (0.20-0.95)].

high-PHA, which may reflect a better immunological status, is associated with improved progression-free survival.

Previous studies have identified several inflammation/ nutrition biomarkers as prognostic factors for cancer. Overweight, in patients with colorectal cancer or nasopharyngeal carcinoma, consistently shows favourable prognosis $(13,14)$. High NLR is also associated with an adverse OS in many solid tumours (15), whereas low baseline NLR is associated with favourable outcomes for metastatic melanoma patients treated with ipilimumab (16-18). CRP is an independent prognostic 
Table IV. Univariate and multivariate analyses of risk factors for time to treatment failure.

\begin{tabular}{lccc}
\hline & $\begin{array}{c}\text { Univariate analysis } \\
\text { HR }(95 \% \mathrm{CI})\end{array}$ & $p$-Value & $\begin{array}{c}\text { Multivariate analysis } \\
\text { HR }(95 \% \mathrm{CI})\end{array}$ \\
\hline Gender female & $1.06(0.47,2.37)$ & 0.888 & \\
Age $\geq 72$ years & $0.81(0.46,1.43)$ & 0.463 & \\
Performance Status of $2-3$ & $2.78(1.49,5.17)$ & 0.001 & $1.56(0.80,3.04)$ \\
Histology of adenocarcinoma & $0.91(0.49,1.69)$ & 0.758 & \\
PD-L1 staining $\geq 50 \%$ & $1.21(0.66,2.24)$ & 0.538 & $0.59(0.31,1.12)$ \\
Stage of IV & $0.49(0.28,0.88)$ & 0.017 & \\
Treatment line of first line & $0.66(0.37,1.17)$ & 0.157 & 0.109 \\
Body mass index $\geq 25 \mathrm{~kg} / \mathrm{m}^{2}$ & $0.85(0.48,1.51)$ & 0.584 & \\
Neutrophil-to-lymphocyte ratio $\geq 3.6$ & $1.97(1.09,3.57)$ & 0.025 & \\
$*$ Serum albumin $(\mathrm{g} / \mathrm{dl})$ & $0.4(0.22,0.73)$ & 0.003 & $2.46(1.26,4.82)$ \\
C-reactive protein $\geq 0.6 \mathrm{mg} / \mathrm{dl}$ & $3.35(1.80,6.23)$ & $<0.001$ & 0.187 \\
IGR (IU/ml) level $>10$ & $0.48(0.25,0.90)$ & 0.023 & $0.008(0.24,0.95)$ \\
\hline
\end{tabular}

IGR: Interferon gamma release; CI: confidence interval. *Serum albumin was excluded from the multivariate analysis because of missing data for 2 individuals.

factor for survival in patients with advanced NSCLC receiving palliative first-line chemotherapy $(19,20)$. CRP/albumin ratio (CAR) is a potential independent predictor for disease progression and death in patients with operable NSCLC (21). In a meta-analysis (22), CAR was suggested as a potential prognostic marker in solid cancers.

In this study, IGR levels were significantly associated with high BMI, NLR, and CRP, and low s-Alb; therefore, using IGR as a biomarker would integrate these independent biomarkers. A high level of NLR and CRP, and a low level of s-Alb have been associated with systemic inflammation $(23,24)$. This study indicated that patients with chronic systemic inflammation would show poor outcomes for ICItx. Thus, IGR levels represent a potential biomarker to measure treatment efficacy in these patients.

Furthermore, IGR level is an improved biomarker, as compared to other biomarkers. Firstly, IGR level directly examines the activity of viable $\mathrm{T}$ cells; therefore, it is an index of immune function. Secondly, IGR levels change dynamically during ICI-tx, depending on the immune status of the patients as shown in our previous studies $(4,5)$. Thus, while other markers for ICI-tx efficacy are static biomarkers, IGR levels are dynamic, and more accurate.

Fujita et al. (25) reported that the incidence of active MTB in lung cancer patients receiving ICIs is $1.7 \%$. They emphasized on monitoring patients with a positive IGRA test before ICI-tx for development of TB during immunotherapy. In the present study, 7 patients had a positive IGRA test. However, as of March 31, 2020, none of these patients had developed MTB. Close monitoring for future MTB development will continue, as suggested by Fujita et al. (25).

Our study has several limitations that must be considered. First, the sample size in this study was small. Second, the population of patients enrolled in this study was heterogeneous. Finally, we did not examine cytokines and interleukins other than IFN- $\gamma$.

To conclude, we recommend a pre-treatment IGRA level of $10 \mathrm{IU} / \mathrm{ml}$ as a cut-off value to identify patients who will respond favourably to receiving ICI-tx. IGR level is a dynamic biomarker that integrates inflammation/nutrition biomarkers such as BMI, NLR, CRP, and s-Alb. Close monitoring of $M T B$ development is necessary in patients with a positive IGRA.

\section{Conflicts of Interest}

T.H. received honoraria and research funding as a primary investigator at this institution from Ono Pharmaceutical Co. Ltd. (Osaka, Japan), Lilly Japan Co. Ltd. (Hyogo, Japan), AstraZeneca Co. Ltd. (Osaka, Japan), Taiho Pharmaceutical Co. Ltd. (Tokyo, Japan), Chugai Pharmaceutical Co. Ltd. (Tokyo, Japan), and MSD Oncology Co. Ltd. (Tokyo, Japan). TH did not receive honoraria and research funding associated with this study. The other Authors have no conflicts of interest to declare in relation to this study.

\section{Authors' Contributions}

All Authors were involved in the conception and design of the study, the acquisition of data, or the analysis and interpretation of data; drafting the article or revising it critically; and final approval of the version to be submitted. T.H., T.K, H.S., S.N., A.T, N.M., S.H., and N.O. collected clinical data. H.Y., A.M. and Y.T. performed measurement of QuantiFERON ${ }^{\circledR}$-TB Gold Plus. H.K. performed blood examination. K.K made the pathological diagnoses. T.H., T.K., H.S., and T.T. performed the statistical analyses.

\section{Acknowledgements}

The Authors wish to thank the patients and their families. The Authors also extend their appreciation to Mrs. Yuko Tani, who is 
their secretary and summarized the data. The Authors thank Editage (www.editage.jp) for English language editing.

\section{References}

1 Barber DL, Sakai S, Kudchadkar RR, Fling SP, Day TA, Vergara JA, Ashkin D, Cheng JH, Lundgren LM, Raabe VN, Kraft CS, Nieva JJ, Cheever MA, Nghiem PT and Sharon E: Tuberculosis following pd-1 blockade for cancer immunotherapy. Sci Transl Med 11(475): eaat2702, 2019. PMID: 30651320. DOI: 10.1126/scitranslmed.aat2702

2 Sakai S, Kauffman KD, Sallin MA, Sharpe AH, Young HA, Ganusov VV and Barber DL: CD4 T cell-derived IFN-gamma plays a minimal role in control of pulmonary mycobacterium tuberculosis infection and must be actively repressed by PD-1 to prevent lethal disease. PLoS Pathog 12(5): e1005667, 2016. PMID: 27244558. DOI: 10.1371/journal.ppat.1005667

3 Tousif S, Singh Y, Prasad DV, Sharma P, Van Kaer L and Das G: T cells from programmed death-1 deficient mice respond poorly to mycobacterium tuberculosis infection. PLoS One 6(5): e19864, 2011. PMID: 21589883. DOI: 10.1371/journal.pone.0019864

4 Hirashima T, Kanai T, Suzuki H, Yoshida H, Matsushita A, Kawasumi H, Samejima Y, Noda Y, Nasu S, Tanaka A, Morishita N, Hashimoto S, Kawahara K, Tamura Y, Okamoto N and Tanaka T: The levels of interferon-gamma release as a biomarker for non-small-cell lung cancer patients receiving immune checkpoint inhibitors. Anticancer Res 39(11): 6231-6240, 2019. PMID: 31704852. DOI: 10.21873/anticanres.13832

5 Kanai T, Suzuki H, Yoshida H, Matsushita A, Kawasumi H, Samejima Y, Noda Y, Nasu S, Tanaka A, Morishita N, Hashimoto S, Kawahara K, Tamura Y, Okamoto N, Tanaka T and Hirashima T: Significance of quantitative interferon-gamma levels in non-small-cell lung cancer patients' response to immune checkpoint inhibitors. Anticancer Res 40(5): 2787-2793, 2020. PMID: 32366425. DOI: 10.21873/anticanres.14251

6 Huang HC, Su WJ, Chiang CL, Feng JY, Huang HY, Lin CH, Lin $\mathrm{SH}$, Cheng CY and Chiu CH: The predictive value of the interferongamma release assay for chemotherapy responses in patients with advanced non-small-cell lung cancer. Lung Cancer 115: 64-70, 2018. PMID: 29290264. DOI: 10.1016/j.lungcan.2017.11.016

7 Langan EA, Graetz V, Allerheiligen J, Zillikens D, Rupp J and Terheyden P: Immune checkpoint inhibitors and tuberculosis: An old disease in a new context. Lancet Oncol 21(1): e55-e65, 2020. PMID: 31908308. DOI: 10.1016/S1470-2045(19)30674-6

8 Osaka Habikino Medical Center: Opt-out. Available at: http://www.ra.opho.jp/hospital/110/ [Last accessed June 18, 2020]

9 World Health Organization: Body mass index - BMI. Available at: https://www.euro.who.int/en/health-topics/disease-prevention/ nutrition/a-healthy-lifestyle/body-mass-index-bmi [Last accessed June 18, 2020]

10 QIAGEN: QuantiFERON-TB Gold. Available at: www. quantiferon.com/products/quantiferon-tb-gold/ [Last accessed August 31, 2020]

11 QIAGEN: What is QuantiFERON-TB Gold Plus? Available at: https://www.quantiferon.com/products/quantiferon-tb-gold-plusqft-plus/. [Last accessed August 31, 2020]

12 QIAGEN: Package Inserts. Available at: https://www. quantiferon.com/jp/cd/provider-resources/quantiferon-tb-goldplus/package-inserts/ [Last accessed August 31, 2020]
13 Kroenke CH, Neugebauer R, Meyerhardt J, Prado CM, Weltzien E, Kwan ML, Xiao J and Caan BJ: Analysis of body mass index and mortality in patients with colorectal cancer using causal diagrams. JAMA Oncol 2(9): 1137-1145, 2016. PMID: 27196302. DOI: $10.1001 /$ jamaoncol.2016.0732

14 Huang PY, Wang CT, Cao KJ, Guo X, Guo L, Mo HY, Wen BX, Wu YS, Mai HQ and Hong MH: Pretreatment body mass index as an independent prognostic factor in patients with locoregionally advanced nasopharyngeal carcinoma treated with chemoradiotherapy: Findings from a randomised trial. Eur J Cancer 49(8): 1923-1931, 2013. PMID: 23434149. DOI: 10.1016/j.ejca.2013.01.027

15 Templeton AJ, McNamara MG, Seruga B, Vera-Badillo FE, Aneja P, Ocana A, Leibowitz-Amit R, Sonpavde G, Knox JJ, Tran B, Tannock IF and Amir E: Prognostic role of neutrophilto-lymphocyte ratio in solid tumors: A systematic review and meta-analysis. J Natl Cancer Inst 106(6): dju124, 2014. PMID: 24875653. DOI: $10.1093 /$ jnci/dju124

16 Ferrucci PF, Gandini S, Battaglia A, Alfieri S, Di Giacomo AM, Giannarelli D, Antonini Cappellini GC, De Galitiis F, Marchetti P, Amato G, Lazzeri A, Pala L, Cocorocchio E and Martinoli C: Baseline neutrophil-to-lymphocyte ratio is associated with outcome of ipilimumab-treated metastatic melanoma patients. $\mathrm{Br}$ J Cancer 112(12): 1904-1910, 2015. PMID: 26010413. DOI: 10.1038/bjc. 2015.180

17 Khoja L, Atenafu EG, Templeton A, Qye Y, Chappell MA, Saibil S, Hogg D, Butler MO and Joshua AM: The full blood count as a biomarker of outcome and toxicity in ipilimumab-treated cutaneous metastatic melanoma. Cancer Med 5(10): 2792-2799, 2016. PMID: 27683208. DOI: 10.1002/cam4.878

18 Ferrucci PF, Ascierto PA, Pigozzo J, Del Vecchio M, Maio M, Antonini Cappellini GC, Guidoboni M, Queirolo P, Savoia P, Mandala M, Simeone E, Valpione S, Altomonte M, Spagnolo F, Cocorocchio E, Gandini S, Giannarelli D and Martinoli C: Baseline neutrophils and derived neutrophil-to-lymphocyte ratio: Prognostic relevance in metastatic melanoma patients receiving ipilimumab. Ann Oncol 27: 732-738, 2016. PMID: 28379318. DOI: $10.1093 /$ annonc/mdw016

19 Koch A, Fohlin H and Sorenson S: Prognostic significance of creactive protein and smoking in patients with advanced nonsmall cell lung cancer treated with first-line palliative chemotherapy. J Thorac Oncol 4(3): 326-332, 2009. PMID: 19155996. DOI: $10.1097 / J T O .0 b 013 \mathrm{e} 31819578 \mathrm{c} 8$

20 Shrotriya S, Walsh D, Bennani-Baiti N, Thomas S and Lorton C: C-reactive protein is an important biomarker for prognosis tumor recurrence and treatment response in adult solid tumors: A systematic review. PLoS One 10(12): e0143080, 2015. PMID: 26717416. DOI: 10.1371/journal. pone. 0143080

21 Zhang F, Ying L, Jin J, Chen K, Zhang N, Wu J, Zhang Y and Su D: The c-reactive protein/albumin ratio predicts long-term outcomes of patients with operable non-small cell lung cancer. Oncotarget 8(5): 8835-8842, 2017. PMID: 27823974. DOI: 10.18632 /oncotarget.13053

22 Li N, Tian GW, Wang Y, Zhang H, Wang ZH and Li G: Prognostic role of the pretreatment c-reactive protein/albumin ratio in solid cancers: A meta-analysis. Sci Rep 7: 41298, 2017. PMID: 28128229. DOI: 10.1038/srep41298

23 Zhang S, Diao J, Qi C, Jin J, Li L, Gao X, Gong L and Wu W: Predictive value of neutrophil to lymphocyte ratio in patients 
with acute ST segment elevation myocardial infarction after percutaneous coronary intervention: A meta-analysis. BMC Cardiovasc Disord 18(1): 75, 2018. PMID: 29716535. DOI: 10.1186/s12872-018-0812-6

24 Zhu Y, Zhou S, Liu Y, Zhai L and Sun X: Prognostic value of systemic inflammatory markers in ovarian cancer: A PRIZMAcompliant meta-analysis and systematic review. BMC Cancer 18(1): 443, 2018. PMID: 29669528. DOI: 10.1186/s12885-0184318-5
25 Fujita K, Yamamoto Y, Kanai O, Okamura M, Hashimoto M, Nakatani K, Sawai S and Mio T: Incidence of active tuberculosis in lung cancer patients receiving immune checkpoint inhibitors. Open Forum Infect Dis 7(5): ofaa126, 2020. PMID: 32391404. DOI: $10.1093 /$ ofid/ofaa126

Received September 26, 2020

Revised October 10, 2020

Accepted October 12, 2020 